\title{
HSE Assessment and Improvement in Shot Blasting Process
}

\author{
C.Krishnakumar ${ }^{1}$, S.Chandralekha ${ }^{2}$ \\ ${ }^{1}$ M.E (Industrial Safety Engineering), \\ K.S.Rangasamy College Of Technology, Tamilnadu, India \\ ${ }^{2}$ Assistant Professor, Department Of Mechatronics Engineering, \\ K.S.Rangasamy College of Technology, Tamilnadu, India
}

\begin{abstract}
In foundry industry the shot blasting process plays a vital role for clean, strengthen or polish the metal, in foundries the handling of shot blasting machines having most hazards related to health, safety \& Environment are involved. It may cause eye, skin and respiratory tract irritation to health. Particularly in aluminium foundries the aluminium dust emission product is a white crystalline powder and it has the characteristics of forming explosive dust in the air mixtures. In this dust emission the acute effects are health hazards; particulates may cause irritation to the eyes, nose, throat and lungs. In case of inhalation by the operators and co-workers it may be irritating to the respiratory tract and cause respiratory disorder. In case of chronic effects it may leads to lung cancer and the risk of severe effects depends on duration and level of exposure.The route of entry is inhalation, skin and eye contact and the affected target organs are respiratory system, lungs. Skin \& eyes. The unusual fire \& explosion hazards are dust in high concentrations may form explosive mixtures with air. The hazardous combustion products are listed as irritating gases, vapors, fumes and oxides of carbon. This project is to reduce the risk level by implementing the assessment and improvement control measures in the shot blasting machines by effective qualitative analysis method.
\end{abstract}

Keywords: Shot Blasting, Hazards, Emission, Exposure, Health Effects.

\section{Introduction}

Aluminium Die casting is a metal casting process that is characterized by forcing molten metal under high pressure into a mold cavity. The mold cavity is created using two hardened tool steel dies which has been machined into shape and work similarly to an injection mold during the process

The casting equipment and the metal dies represent large capital costs and this tends to limit the process to high volume production. Manufacture of parts using die casting is relatively simple, involving only four main steps, which keeps the incremental cost per item low. It is especially suited for a large quantity of small to medium-sized castings, which is why die casting produces more castings than any other casting process. Die castings are characterized by a very good surface finish (by casting standards) and dimensional consistency.

The aluminium dust explosion overpressure will be vented out using a relief vent system [18]. The musculoskeletal disorder among the foundry workers and this cause the symptoms due to highly repetitive work, forceful exertions, lifting and forceful movements, and whole-body vibration are examples of risk factors that have been associated with increased the reporting of WRMSDs.[13]. The exposure to continuous noise leads to hearing loss. Noise has to be classify the effects on ears in three groups which are acoustic trauma, temporary hearing losses and permanent hearing loss.[7].The erosion rates of these ceramic nozzles also depend on the hardness and grain size of the erodent abrasive in sand blasting processes[6]. In the aluminium die casting industry it is a source of metal emissions to the environment that may be toxic to humans and other organisms. Moreover, the industry emits air pollutants, such as nitrogen oxides and carbon dioxide, which cause troposphere ozone formation, acidification, human toxicity and global warming [3].

Aluminium Dust Emission:

\section{Hazards In Shot Blasting Process}

The aluminium dust emission is very dangerous and is explosive while it get ignited and also made some occupational related health issues occur due to inhale the dust.

Musculoskeletal Problem Due To Handling Of Vibrating Tool Or Part

By handling of the vibration tool for a prolonged period cause musculoskeletal problems to the worker

Dust Inhalation

Dust inhalation may cause adverse health effects to the workers.

Noise:

Evaluation by occupational health and safety personnel of noise should be undertaken to identify areas where noise levels may be excessive. Surveys of foundries have shown that the fettling and shakeout operations give rise to considerable noise levels, with potentially harmful effects on the hearing of exposed workers. In 
addition to the workers immediately involved in these processes, people working in the vicinity may be exposed to noise levels well in excess of $85 \mathrm{db}(\mathrm{A})$.

Some fettling workers have been shown to be exposed to levels of noise over $100 \mathrm{db}(\mathrm{A})$; shakeout and knockout processes are typically associated with readings of 90-110 $\mathrm{db}(\mathrm{A})$.Extraction fans, die casting machines, shot blasting machines and shell making equipment may also be a sources of excessive noise

\section{Vibration:}

Pneumatic grinding and chipping tools used in dressing the cooled castings may cause vibration induced health effects in operators. Potentially hazardous vibration equipment may also be utilized in shakeout and core removal operation. Holding the compressor air hose for aluminium oxide shot blast also induced vibration to the worker.

\section{Leakage In Shots:}

At the time of blasting the metal the leakage of shot is a major hazard in the shot blasting machines

\section{Heat Radiation}

Radiant heat is the major contributor to the heat load imposed on the worker by the environment. Convective heat transfer adds to this heat radiant. Protective clothing is worn for protection against the heat radiating from the heat sources and against contact with molten metal. Such clothing greatly restricts the potential for body heats loss via evaporation. The foundry worker experiences a total heat load which is determined by the time spent at each workstation, the intensity of the work, the clothing worn and the immediate workstation environment, including air circulation. If the heat load is sufficiently severe, the effects on health and the performance will occour.These range from decreased concentration to painful cramps, fainting, heat exhaustion and heat stroke.

\section{Physical Injuries:}

Serious burns may result from splashes of molten metal in the melting and pouring areas of the foundries. Frequent, unprotected viewing of white hot metals in furnaces and pouring areas may cause eye cataracts. Eye injuries from molten metal or fragments of metal may occur in the pouring and dressing areas.

During continuous casting process, non ferrous molten metal's, such as copper, aluminium, may explode violently if they contact with water. Such explosions can occur in water cooled furnaces. Whenever the spillages of molten metal occur during the charging of furnaces with wet ingots or scrap metal and whenever the moist tools, moulds or other material come into contact with molten metal. Injuries related to manual handling of materials and injuries due to slip may occur.

\section{Noise Reduction}

The detection of noise emitted from the machine was to examine by the noise level meter and compare it with the previous measurements. The noise level considered in this experiment ranges from $85 \mathrm{db}$ to $105 \mathrm{db}$.It has to be reduced by means of proper engineering judgement. The noise exposure was minimised by insisting the PPE among the machine operators and co- workers those are employed in the machine area.

\section{Ear Plug}

\section{Ppe Used To Reduce Noise}

Ear plug is insisted to the workers to minimise the noise exposure emitted from the shot blasting process and the given PPE is conforming to IS (Indian Standard) 6229:1971 were used. The typical noise level is listed in Table 3.1

Table 3.1 Typical Noise Level

\begin{tabular}{|l|l|}
\hline Location & dB \\
\hline Machine Shop & 90 \\
\hline Manufacturing & 80 \\
\hline Assembly Line & 75 \\
\hline Office & 55 \\
\hline
\end{tabular}

\section{Blast Nozzle - Shot Blast}

Locally available blast nozzle was replaced and conforming to IS 383:1970 were used. The nozzle has to be replaced if the bore has increased $25 \%$ or more. The nozzle size and its efficiencies are listed in Table 3.2

Table 3.2 Properties of Aggregate 


\begin{tabular}{|l|l|l|l|l|l|}
\hline \multicolumn{2}{|l|}{ Nozzle size } & \multicolumn{4}{l|}{ Nozzle pressure } \\
\hline & & $\begin{array}{l}50 \\
\text { Psi }\end{array}$ & $\begin{array}{l}90 \\
\text { Psi }\end{array}$ & $100 \mathrm{psi}$ & $120 \mathrm{psi}$ \\
\hline No.2 & $1 / 8 ”$ & 14 & 24 & 26 & 30 \\
\hline No.3 & $3 / 16 "$ & 32 & 52 & 57 & 67 \\
\hline No.4 & $1 / 4 "$ & 57 & 93 & 103 & 119 \\
\hline No.5 & $5 / 16 "$ & 89 & 145 & 158 & 186 \\
\hline No.6 & $3 / 8 ”$ & 129 & 209 & 229 & 269 \\
\hline No.7 & $7 / 16 "$ & 176 & 285 & 312 & 367 \\
\hline No.8 & $1 / 2 "$ & 229 & 371 & 407 & 478 \\
\hline No.10 & $5 / 8 ”$ & 356 & 580 & 632 & 744 \\
\hline No.12 & $3 / 4 "$ & 516 & 836 & 916 & 1076 \\
\hline Efficiency & $47 \%$ & $86 \%$ & $100 \%$ & $130 \%$ \\
\hline
\end{tabular}

\section{Acoustic Rubber Liner}

Acoustic thick wear resistant rubber liner sheet were used to ensure the noise reduction and ensure the long life of shot blasting chambers. The properties of Acoustic rubber liner sheet is listed in Table 3.3

Table 3.3 Properties of Acoustic rubber liner sheet

\begin{tabular}{|l|l|l|}
\hline S.no & Properties & Values \\
\hline 1 & Length & $(1000 * 2000 * 6) \mathrm{mm}$ \\
\hline 2 & Material & CR \\
\hline 3 & Hardness & 65 \\
\hline 4 & Density & $1.4 \mathrm{~g} / \mathrm{cm}^{3}$ \\
\hline 5 & Color & Black \\
\hline 6 & Tensile Strength & $60 \mathrm{~kg} / \mathrm{cm}^{3}$ \\
\hline 7 & $\begin{array}{l}\text { Elongation } \\
\text { break }(\%), \text { at }\end{array}$ & 250 \\
\hline
\end{tabular}

\section{Dust Emission Reduction}

Hoods and dust collecting bins are properly fitted in position to collect all the travelling dust and remove all the leakage dust in regular basis.

Respirator and goggles are insisted those who are working near the machine area. The emission dust is flammable if it catches ignition causes fire/explosion. Explosion vent to be provided and regularly the dust to be removed.

Flame proof electrical connection to be provided and ensure double earthing for electrical connection. Static dissipater to be provided to eliminate the static discharge.

\section{Shot Leakage Reduction}

The shot blasting chamber has to be maintained properly in a regular frequency and it has to be ensured that the chamber is checked by a competent person to ensure its stability.

\section{Wrmsd}

The castings are handled manually by operator for blasting operation; continuously they are doing the repeated job leads to work related muscular skeletal disorder. It has to be minimised by implementing the job rotation to the operator and provide proper rest pauses.

Repeated ergonomics training provided to the operator and ensure that they were followed the proper working posture at work time has to be noted by behavioural analysis.

\section{Heat Reduction}

The heat radiation has to be controlled by providing hoods and the temperature to be monitored on regularly by dry bulb and wet bulb method to ensure the heat radiation is under normal condition.

\section{Machine Check Points}

The machine has to be checked on regular basis with the following check points. The check points are listed in table 3.4.

Table 3.4 Check Points

\begin{tabular}{|l|l|l|l|l|}
\hline $\begin{array}{l}\text { S.N } \\
\text { o }\end{array}$ & Check points & YES & NO & Remarks \\
\hline 1 & Explosion Vent & & & \\
\hline 2 & $\begin{array}{l}\text { Exhaust } \\
\text { Provision }\end{array}$ & & & \\
\hline 3 & Shot Leakage & & & \\
\hline
\end{tabular}




\begin{tabular}{|l|l|l|l|l|}
\hline 4 & $\begin{array}{l}\text { Maintenance of } \\
\text { dust Pit }\end{array}$ & & & \\
\hline 5 & $\begin{array}{l}\text { Gauntlets } \\
\text { Availability }\end{array}$ & & & \\
\hline 6 & Double Earthing & & & \\
\hline 7 & $\begin{array}{l}\text { Manometer } \\
\text { availability }\end{array}$ & & & \\
\hline 8 & $\begin{array}{l}\text { Nozzle \& Blast } \\
\text { hose Condition }\end{array}$ & & & \\
\hline 9 & $\begin{array}{l}\text { Foot pedal / } \\
\text { Operator platform }\end{array}$ & & & \\
\hline 10 & $\begin{array}{l}\text { Vision window } \\
\text { condition }\end{array}$ & & & \\
\hline 11 & $\begin{array}{l}\text { Guarding } \\
\text { Arrangement }\end{array}$ & & & \\
\hline 12 & $\begin{array}{l}\text { Emergency Push } \\
\text { button }\end{array}$ & & & \\
\hline 13 & $\begin{array}{l}\text { ON/OFF Switch } \\
\text { Condition }\end{array}$ & & & \\
\hline 14 & Area Lighting & & & \\
\hline 15 & Ventilation & & & \\
\hline 16 & Noise Level & & & \\
\hline 17 & $\begin{array}{l}\text { Access/Egress } \\
\text { Condition }\end{array}$ & & & \\
\hline 18 & $\begin{array}{l}\text { PPE Insisted \& } \\
\text { Worn }\end{array}$ & & & \\
\hline 19 & $\begin{array}{l}\text { Rubber Liner } \\
\text { Condition }\end{array}$ & & \\
\hline
\end{tabular}

From the table 3.4, the check points to be checked and ensure the machine was in good condition.

\section{Initial Vs Implementation}

\section{Noise Level}

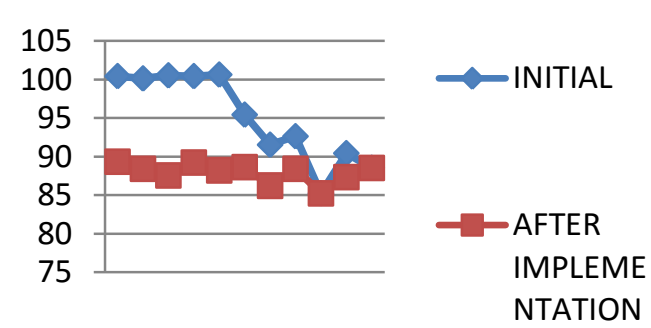

Table 3.5 Noise level Initial vs Implementation

\begin{tabular}{|l|l|l|}
\hline Location & Initial & $\begin{array}{l}\text { After } \\
\text { Implementation }\end{array}$ \\
\hline 1 & 100.4 & 89.3 \\
\hline 2 & 100.1 & 88.4 \\
\hline 3 & 100.5 & 87.5 \\
\hline 4 & 100.4 & 89.2 \\
\hline 5 & 100.6 & 88.2 \\
\hline 6 & 95.4 & 88.6 \\
\hline 7 & 91.5 & 86.2 \\
\hline 8 & 92.6 & 88.4 \\
\hline 9 & 85.2 & 85.2 \\
\hline 10 & 90.4 & 87.3 \\
\hline 11 & 88.5 & 88.5 \\
\hline
\end{tabular}

Figure: Noise level Initial vs Implementation 


\section{Result}

- Regular inspection and maintenance showed that the stability of the machine and ensure that it is free from defects.

- Noise study also showed that there was decrease in $\mathrm{dB}$ when compared with the initial $\mathrm{dB}$ after implement the remedies.

- When compared with behavioral observation among the operators, the training needs to be identified and provided to improve the safety culture.

- The initial noise level showed that some area are under critical situations and need importance to the location it has to be minimized through engineering suggestion

- Training needs to be provided to improve the safety awareness among the operators and co-workers those who are worked in that machine area.

- The usage of PPE also reduced the exposure from dust \& noise emitted from the shot blasting process.

\section{References}

[1]. A.J Bishop (2015), "Particulate emissions within foundries dust arrestment requirements" Dry bag filtration in foundries, Vol. 11, pp. 737-741.

[2]. Adel M.Zakaria (2005), "Evaluation of Occupational hazards in foundries" The journal of the Egyptian public health association, Vol. 80, pp. 434-464.

[3]. Belmira Netoa (2009), "Strategies to reduce the environmental impact of an aluminium pressure die casting planty: A scenario analysis" Journal of Environmental management, Vol. 90, pp. 815-830.

[4]. Belmira Netoa (2009), "Inventory of pollution reduction options for an aluminium pressure die casting plant" Resources,conservation and recycling, Vol. 53, pp. 309-320.

[5]. Beth Rosenberg. (2006), "Ergonomics of abrasive blasting: A comparision of high pressure water and steel shot" Applied Ergonomics, Vol. 37, pp. 659-667.

[6]. D.Fatta (2004), "Industrial pollution and control measures for a foundry in cyprus" Journal of cleaner production, Vol. 12, pp. 2936.

[7]. Deng Jiaxin (2003), "Wear behaviour of ceramic nozzles in sand blasting treatment" Journal of the European ceramic society, Vol. 32, pp. 323-329.

[8]. E.Atmaca (2005), "Industrial noise and its effects on humans" Polish journal of Environmental Studies, Vol. 14, pp. 721-726.

[9]. H.W.Kuo (1998), "Prevalance of and factors related to pneumoconiosis among foundry workers in central taiwan" The science of the Total Environment Vol. 222, pp. 133-139.

[10]. Hung Hsin Liu (2010), "Oxidative damage in foundry workers occupationally co-exposed to PAHs and metals"International Journal in Hygiene Environmental health, Vol. 213, pp. 93-98.

[11]. Jacqueline Patel (1999), "Measuring the noise attenuation of shot blasting helmets" Ann. Occupational Hygiene, Vol. 43, pp.471484 .

[12]. Kwangseok choi (2015), "Experimental study on ignitability of pure aluminium powders due to electrostatic discharges and nitrogen effect" Journal of Loss prevention in the process industries, Vol. 35, pp. 232-235.

[13]. L.Marmo. (2004), "Aluminium dust explosion risk analysis in metal workings" Journal of Loss prevention in the process industries, Vol. 17, pp. 449-465.

[14]. Ling lei (2005), "Risk factors for the prevalence of musculoskeletal disorders among Chinese foundry workers" International journal of industrial ergonomics, Vol. 35, pp. 197-204.

[15]. Myeongseok Yang (2014), "Wet blasting as a deburring process for aluminium" Journal of material processing technology, Vol. 214, pp. 524-530.

[16]. Philippe Julien (2015), "Effect of scale on freely propagating flames in aluminium dust clouds" Journal of Loss prevention in process industries, Vol. 36, pp. 230-236.

[17]. Rajib Biswas (2012), "Assessment of cardiac strain in small scale aluminium casting works" International journal of Occupational safety and health, Vol. 02, pp. 8-13.

[18]. Salvatore Polizzi (2002), "Neurotoxic effects of aluminium among foundry workers and Alzheimer's Diseases" Neuro Toxicology, Vol. 23, pp. 761-774.

[19]. Xing-Qing Yan (2013), "Overpressure charecteristics of aluminium dust explosion vented through a relief pipe" Journal of Loss prevention in the process Industries, Vol. 26, pp. 676-682.

[20]. Ying Huang. (2007), "Combustion of bimodal nano/micron-sized aluminium particles dust in air" Proceedings of the combustion institute, Vol. 31, pp. 2001-2009. 